\title{
Continuous high-dose infusion of doripenem in a pneumonia patient infected by carbapenem-resistant Pseudomonas aeruginosa: a case report
}

Kazutaka Oda ${ }^{1,2}$, Hidenobu Kamohara ${ }^{3}$, Tomomi Katanoda ${ }^{1,2}$, Yumi Hashiguchi', Koji Iwamura ${ }^{1}$, Kisato Nosaka ${ }^{2}$, Hirofumi Jono ${ }^{1}$ and Hideyuki Saito ${ }^{1 *}$

\begin{abstract}
Background: Despite the high mortality of patients with sepsis and carbapenem-resistant bacteria infection, appropriate antimicrobial therapies are yet to be established. Here, we have reported the case of a patient with pneumonia that subsequently developed by carbapenem-resistant Pseudomonas aeruginosa infection and was treated with a continuous high-dose infusion of doripenem.

Case presentation: We started a continuous intravenous infusion of doripenem $3 \mathrm{~g} / \mathrm{day}$ although the 59 -year-old woman (body weight, $45 \mathrm{~kg}$ ) had developed septic acute kidney injury, followed by continuous renal replacement therapy (the effluent flow rate was $650 \mathrm{~mL} / \mathrm{h}$ ). The minimum inhibitory concentration (MIC) of doripenem was 8 $\mathrm{mg} / \mathrm{L}$. The concentration of unbound doripenem in the serum was measured by using high-performance liquid chromatography. Twenty hours after the initial dose, the patient's serum level of doripenem was $47.8 \mu \mathrm{g} / \mathrm{mL}$; the level decreased to $33.6 \mu \mathrm{g} / \mathrm{mL}$ at $111 \mathrm{~h}$ after initial dosing. The unbound doripenem concentration in the serum was maintained four times above the MIC throughout the treatment. After the completion of 11 days of dosing, the patient was discharged from the intensive care unit. During the treatment period, the MIC remained at $8 \mathrm{mg} / \mathrm{L}$.

Conclusions: A continuous high-dose infusion of doripenem is a potentially efficient strategy for the treatment of antimicrobial-resistant bacteria. Moreover, therapeutic drug monitoring may be useful for patients displaying variable pharmacokinetics, because the MIC is generally high in resistant bacteria.
\end{abstract}

Keywords: Doripenem, Continuous infusion, High-dose, Therapeutic drug monitoring, Continuous renal replacement therapy, Acute kidney injury

\section{Background}

The mortality rate of patients with sepsis is reported to be greater than 10\% [1]; therefore, appropriate antimicrobial therapies must be applied to ensure a successful cure. Owing to the broad-spectrum antibacterial activity of carbapenems, they are often used for the treatment of patients with sepsis; however, carbapenemresistant bacteria have emerged as a major concern for medical practitioners [2]. A mortality rate of up to $21.4 \%$

\footnotetext{
* Correspondence: saitohide@kuh.kumamoto-u.ac.jp

${ }^{1}$ Department of Pharmacy, Kumamoto University Hospital, 1-1-1, Honjo,

Chuo-ku, Kumamoto, Japan

Full list of author information is available at the end of the article
}

has been reported for patients with sepsis and carbapenem-resistant Pseudomonas aeruginosa infection [2]. Despite the available treatment options for $P$. aeruginosa, monotherapy with aminoglycosides was reported to result in a higher mortality rate than that of combination therapies [2]. Although colistin is a potential antibiotic treatment for $P$. aeruginosa, adverse reactions, such as nephrotoxicity and neurotoxicity, are of great concern [3]. Therefore, appropriate antimicrobial therapies must urgently be established for patients with sepsis and carbapenem-resistant $P$. aeruginosa infection.

An adult female patient developed pneumonia and, subsequently, infection by a $P$. aeruginosa strain that

(C) The Author(s). 2019 Open Access This article is distributed under the terms of the Creative Commons Attribution 4.0 International License (http://creativecommons.org/licenses/by/4.0/), which permits unrestricted use, distribution, and 
was resistant to both fluoroquinolones and carbapenems. In the 14 days after diagnosis, she was administered tobramycin (a type of aminoglycoside), which has a minimum inhibitory concentration (MIC) of $1 \mathrm{mg} / \mathrm{L}$. However, the clinical effect was poor: the patient developed respiratory failure and acute kidney injury (AKI), and she was then transferred to our intensive care unit (ICU). The MIC of doripenem (a type of carbapenem [4]) was at a level at which the strain was resistant (8 $\mathrm{mg} / \mathrm{L}$ ); some reports have shown that meropenem (a carbapenem, with an MIC of $>8 \mathrm{mg} / \mathrm{L}$ in this case) was successfully cured at a high dose by keeping the serum meropenem concentration above the MIC against $P$. aeruginosa $[5,6]$.

In this study, we have reported a case of a successful cure by the application of a continuous high-dose infusion of doripenem in addition to tobramycin administration.

\section{Case presentation}

Sixty-three days before starting therapy for this infection, a 59-year-old female patient had been discharged on Day 22 post-surgery in our ICU following a mitral valve replacement. However, at 41 days after discharge, she developed pneumonia due to infection by $P$. aeruginosa, and thus returned to the ICU, where she had to be kept on mechanical ventilation (owing to respiratory failure) and continuous renal replacement therapy (CRRT; owing to AKI). A dosing strategy for doripenem was calculated to determine the continuous infusion to achieve a certain target serum concentration of the unbound drug, which was set to $32 \mu \mathrm{g} / \mathrm{mL}$, i.e., four times higher than the actual MIC ( $8 \mathrm{mg} / \mathrm{L})$ [7]. Here, if the maximal licensed dose in Japan ( 3 g/day) would be delivered by continuous intravenous infusion $(1 \mathrm{~g} / 80 \mathrm{~mL}$ of normal saline $/ 8 \mathrm{~h} ; 10 \mathrm{~mL} / \mathrm{h}$, every $8 \mathrm{~h}$ ), the target concentration could only be achieved when the doripenem total clearance (CLtot) was $<3.6 \mathrm{~L} / \mathrm{h}$. However, previous reports have indicated a doripenem clearance of $2.7-5.9 \mathrm{~L} / \mathrm{h}$ by the body $\left(\mathrm{CL}_{\mathrm{BODY}}\right)$ [8-12]; doripenem clearance by CRRT $\left(\mathrm{CL}_{\mathrm{CRRT}}\right)$ in this case was calculated to be $0.6 \mathrm{~L} / \mathrm{h}$ based on the effluent flow rate of CRRT [13]. Therefore, the probability that the patient's CLtot was $<3.6 \mathrm{~L} / \mathrm{h}$ was low. Furthermore, Monte Carlo simulation computed by $\mathrm{R}$ (ver. 3.5.3, https://www.r-project.org/) estimated that there was a $7.6 \%$ probability of achieving $32 \mu \mathrm{g} / \mathrm{mL}$ of unbound doripenem by using the population pharmacokinetic model for doripenem reported by Roberts et al. [11]. Therefore, therapeutic drug monitoring (TDM) was applied. The time course of the values for the concentration of unbound doripenem in the serum and the values from other laboratory tests during the patient's stay at the ICU are presented in Fig. 1. The samples were prepared by ultrafiltration using a Nanosep Omega $10 \mathrm{~K}$ and the concentrations of unbound doripenem in the serum were quantified by highperformance liquid chromatography [14]. The concentration of unbound doripenem was $47.8 \mu \mathrm{g} / \mathrm{mL}$ at $20 \mathrm{~h}$ after the dose administration started. The concentration decreased to $33.6 \mu \mathrm{g} / \mathrm{mL}$ at $111 \mathrm{~h}$, although these concentrations were maintained at levels that were four times higher than the MIC. Continuous infusion of doripenem was performed for 11 days, after which the patient was discharged from the ICU. After the end of the continuous infusion of doripenem, the MIC against $P$. aeruginosa detected in her sputum was $8 \mathrm{mg} / \mathrm{L}$, which was not elevated.
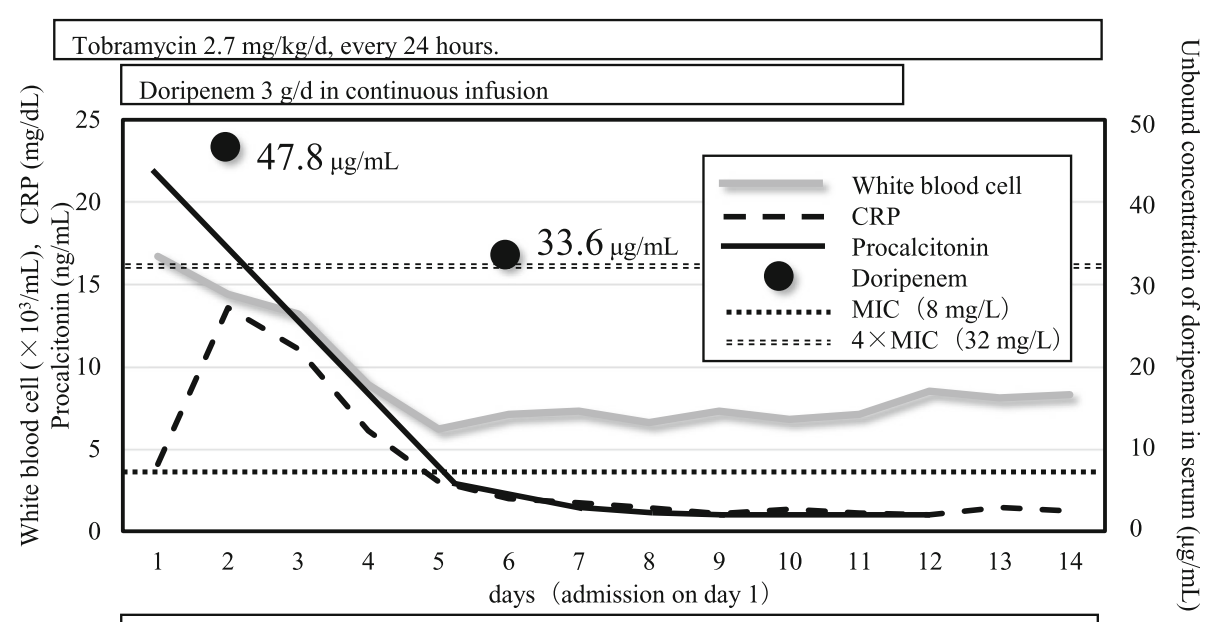

CRRT (blood flow rate $80 \mathrm{~mL} / \mathrm{min}$, effluent flow rate $650 \mathrm{~mL} / \mathrm{hr}$, AN69-ST $1.5 \mathrm{~m}^{2}$ )

Fig. 1 Time course of values for doripenem and other laboratory tests. The concentration of unbound doripenem in serum was $47.8 \mu \mathrm{g} / \mathrm{mL}$ at 20 $\mathrm{h}$ after dosing was started, and decreased to $33.6 \mu \mathrm{g} / \mathrm{mL}$ at $111 \mathrm{~h}$. All biomarkers that acted as an indicator of infection were included in the calculations for the respective normal ranges. The serum concentration of tobramycin was measured on Day 1 before the admission of the patient to the ICU (peak, $16.5 \mu \mathrm{g} / \mathrm{mL}$; trough, $4.3 \mu \mathrm{g} / \mathrm{mL}$ ); the tobramycin dose was then decreased from $5.3 \mathrm{mg} / \mathrm{kg} / \mathrm{day}$ to $2.7 \mathrm{mg} / \mathrm{kg} / \mathrm{day}$. CRP, Creactive protein; CRRT, continuous renal replacement therapy; AN69-ST, a dialyzer membrane made by polyacrylonitrile (surface-treated) 


\section{Discussion and conclusions}

In this case study, we have reported that a continuous high-dose infusion of doripenem provided a successful cure for a patient who had developed pneumonia and doripenem-resistant $P$. aeruginosa infection.

Although colistin may be used as an antibiotic against carbapenem-resistant $P$. aeruginosa, it is reported to cause adverse reactions, such as nephrotoxicity and neurotoxicity [3]. Therefore, colistin use is only recommended in when other antibiotics cannot be used [3]. To the best of our knowledge, only a few reports are available on the dose-dependent adverse reactions of doripenem; therefore, high-dose doripenem administration may be safer than the normal dosage of colistin. To date, the pharmacokinetic/pharmacodynamic (PK/PD) target of beta lactams for successful bactericidal activity has been the time for which the unbound drug concentration above the MIC ( $\% f \mathrm{~T}>\mathrm{MIC}$ ), with a target value of $40 \%$ for carbapenems [15]. The PK/PD target has been now been updated to suggest that the concentration of unbound drug should be more than four times higher than the MIC $(\% f T>4 \times M I C)$ for the maximal therapeutic effect. Therefore, a target value of $60 \%$ or $100 \%$ has been advocated [7]. As the unbound fraction of doripenem has been reported to be $91.1 \%$ [4], we aimed to maintain a concentration of unbound doripenem more than four times higher than the MIC by using a continuous infusion $(32 \mathrm{mg} / \mathrm{L})$.

Previous reports have suggested a variety of dosing strategies for doripenem in patients with CRRT [8-12]. However, only a small amount of information is available for doripenem-resistant $P$. aeruginosa. In this case, although we started from the maximal licensed dose ( $3 \mathrm{~g} /$ day), the probability of achieving the target concentration appeared to be low [8-13]; therefore, we applied TDM.

TDM was conducted by using serum samples taken for other laboratory tests; CLtot was calculated to be 2.4 $\mathrm{L} / \mathrm{h}$ at the time when the concentration of unbound doripenem was $47.8 \mu \mathrm{g} / \mathrm{mL}$ in the serum. The equation is presented below.

$$
\begin{gathered}
" \text { CLtot }=\text { dose }(125 \mathrm{mg} / \mathrm{h}) \times \text { unbound fraction }(0.911) / \\
\text { unbound concentration }(47.8 \mathrm{mg} / \mathrm{L}) "
\end{gathered}
$$

The $\mathrm{CL}_{\text {CRRT }}$ was calculated to be $0.6 \mathrm{~L} / \mathrm{h}$ from the effluent flow rate of CRRT. The equation was described below.

"CL $L_{C R R T}=$ effluent flow rate $(0.65 L / h) \times$ unbound fraction $(0.911) "$

Therefore, $\mathrm{CL}_{\mathrm{BODY}}$ was calculated to be $1.8 \mathrm{~L} / \mathrm{h}$ $\left(C L_{B O D Y}=C L\right.$ tot $\left.-C L_{C R R T}\right)$. Because CLtot and $C L_{\text {BODY }}$ were smaller than the assumption and $\% f \mathrm{~T}>4 \times \mathrm{MIC}$ was $100 \%$, further optimization of the dose was not necessary. In contrast, kidney function improved as demonstrated by the alterations in both the urine output (first day, $56 \mathrm{~mL} /$ day; 6 days later, $498 \mathrm{~mL} /$ day) and serum creatinine levels (first day, $0.97 \mathrm{mg} / \mathrm{dL}$; 6 days later, $0.79 \mathrm{mg} / \mathrm{dL}$ ) during therapy. The improved kidney function might have resulted in the decreased in the concentration of unbound doripenem in the serum to $33.6 \mu \mathrm{g} / \mathrm{mL}$, when CLtot, $\mathrm{CL}_{\mathrm{CRRT}}, \mathrm{CL}_{\mathrm{BODY}}$, and $\% f \mathrm{~T}>$ $4 \times \mathrm{MIC}$ was calculated to be $3.4 \mathrm{~L} / \mathrm{h}, 0.6 \mathrm{~L} / \mathrm{h}, 2.8 \mathrm{~L} / \mathrm{h}$, and $100 \%$, respectively. Importantly, because the initial serum creatinine level was not abnormally high, it was difficult to estimate kidney function precisely in a patient with CRRT. Moreover, the concentration of unbound doripenem in the serum 6 days after the initial dose decreased to a level that was almost near the lower boundary of the target concentration, indicating that CLtot and $\mathrm{CL}_{\mathrm{BODY}}$ varied during therapy. Collectively, the application of TDM in combination with the continuous infusion of doripenem may be useful in patients with CRRT.

This study had several limitations. First, the safety of a continuous high-dose infusion of doripenem has not been confirmed. Thus, careful intervention, such as TDM, is required. Second, the concomitant use of tobramycin may play a key role in the provision of a successful cure and the prevention of emerging resistant $P$. aeruginosa strains rather than the administration of a continuous high-dose infusion of doripenem [16]. In contrast, it has been reported that the concomitant use of aminoglycosides with carbapenems can result in negative therapeutic effects [16]. Therefore, further studies of a continuous high-dose infusion of doripenem should be performed.

In conclusion, this was the first case in which a continuous high-dose infusion of doripenem provided a successful cure against pneumonia caused by doripenemresistant $P$. aeruginosa. Moreover, TDM may be useful for patients with variable pharmacokinetics because the $\mathrm{MIC}$ is generally high in resistant bacteria.

\footnotetext{
Abbreviations

$\% f \mathrm{fT}>4 \times \mathrm{MIC}$ : Time of unbound drug concentration above $4 \times \mathrm{MIC} ; \% \mathrm{fT}>$ MIC: Time of unbound drug concentration above MIC; AKI: Acute kidney injury; AN69-ST: A dialyzer membrane made by polyacrylonitrile (surfacetreated); $\mathrm{CL}_{\text {BODY: }}$ Clearance by body; $\mathrm{CL}_{\text {CRRT: }}$ Clearance by continuous renal replacement therapy; CLtot: Total clearance; CRRT: Continuous renal replacement therapy; ICU: Intensive care unit; MIC: Minimum inhibitory concentration; PK/PD: Pharmacokinetic/pharmacodynamic; TDM: Therapeutic drug monitoring

Acknowledgements

Not applicable.
}

Authors' contributions

$\mathrm{KO}, \mathrm{TK}, \mathrm{YH}$, and $\mathrm{KI}$ analyzed and interpreted the patient data regarding the pharmacokinetics of doripenem. HK diagnosed and treated the pneumonia. $\mathrm{KO}$ and $\mathrm{HJ}$ were the major contributors in writing the manuscript. $\mathrm{KO}, \mathrm{HJ}$, 
and HS contributed new reagents and analytical tools. All authors read and approved the final manuscript.

\section{Funding}

This work was supported by a Grant-in-Aid for Young Scientists (B) 16 K19615 from the Ministry of Education, Culture, Sports, Science, and Technology of Japan.

\section{Availability of data and materials}

The datasets used and/or analyzed during the current study are available from the corresponding author upon reasonable request.

\section{Ethics approval and consent to participate}

This case study and the utilization of rest of patient serum for TDM were approved by The Institutional Review Board, Kumamoto University Hospital. (Approval No. 2413).

\section{Consent for publication}

Written informed consent was obtained from the patient afterwards.

\section{Competing interests}

The authors declare that they have no competing interests.

\section{Author details}

${ }^{1}$ Department of Pharmacy, Kumamoto University Hospital, 1-1-1, Honjo, Chuo-ku, Kumamoto, Japan. ${ }^{2}$ Department of Infection Control, Kumamoto University Hospital, 1-1-1, Honjo, Chuo-ku, Kumamoto, Japan. ${ }^{3}$ Department of Critical Care Medicine, Kumamoto University Hospital, 1-1-1, Honjo, 860-8556 Chuo-ku, Kumamoto, Japan.

Received: 5 April 2019 Accepted: 11 June 2019

Published online: 08 July 2019

\section{References}

1. Singer M, Deutschman CS, Seymour CW, Shankar-Hari M, Annane D, Bauer $M$, et al. The third international consensus definitions for sepsis and septic shock (Sepsis-3). JAMA. 2016;315:801-10. https://doi.org/10.1001/jama.2016. 0287.

2. Britt NS, Ritchie DJ, Kollef MH, Burnham CA, Durkin MJ, Hampton NB, et al. Importance of site of infection and antibiotic selection in the treatment of carbapenem-resistant Pseudomonas aeruginosa sepsis. Antimicrob Agents Chemother. 2018;62:e02400-17. https://doi.org/10.1128/AAC.02400-17.

3. Aggarwal $R$, Dewan A. Comparison of nephrotoxicity of colistin with polymyxin B administered in currently recommended doses: a prospective study. Ann Clin Microbiol Antimicrob. 2018;17:15. https://doi.org/10.1186/ s12941-018-0262-0.

4. Zhanel GG, Wiebe R, Dilay L, Thomson K, Rubinstein E, Hoban DJ, et al. Drugs. 2007:67:1027-52. https://doi.org/10.2165/00003495-200767070-00006.

5. Taccone FS, Cotton F, Roisin S, Vincent JL, Jacobs F. Optimal meropenem concentrations to treat multidrug-resistant Pseudomonas aeruginosa septic shock. Antimicrob Agents Chemother. 2012;56:2129-31. https://doi.org/10. 1128/AAC.06389-11.

6. Saçar S, Turgut H, Cenger DH, Coşkun E, Asan A, Kaleli I. Successful treatment of multidrug resistant Acinetobacter baumannii meningitis. J Infect Dev Ctries. 2007;1:342-4. https://doi.org/10.3855/jidc.376.

7. Sinnollareddy MJ, Roberts MS, Lipman J, Roberts JA. Beta-lactam pharmacokinetics and pharmacodynamics in critically ill patients and strategies for dose optimization: a structured review. Clin Exp Pharmacol Physiol. 2012:39:489-96. https://doi.org/10.1111/j.1440-1681.2012.05715.x.

8. Hidaka S, Goto K, Hagiwara S, Iwasaka H, Noguchi T. Doripenem pharmacokinetics in critically ill patients receiving continuous hemodiafiltration (CHDF). Yakugaku Zasshi. 2010;130:87-94. https://doi.org/ 10.1248/yakushi.130.87

9. Cirillo I, Vaccaro N, Balis D, Redman R, Matzke GR. Influence of continuous venovenous hemofiltration and continuous venovenous hemodiafiltration on the disposition of doripenem. Antimicrob Agents Chemother. 2011;55: 1187-93. https://doi.org/10.1128/AAC.01063-10.

10. Ohchi Y, Hidaka S, Goto K, Shitomi R, Nishida T, Abe T, et al. Effect of hemopurification rate on doripenem pharmacokinetics in critically ill patients receiving high-flow continuous hemodiafiltration. Yakugaku Zasshi. 2011;131:1395-9. https://doi.org/10.1248/yakushi.131.1395.
11. Roberts JA, Udy AA, Bulitta JB, Stuart J, Jarrett P, Starr T, et al. Doripenem population pharmacokinetics and dosing requirements for critically ill patients receiving continuous venovenous hemodiafiltration. J Antimicrob Chemother. 2014;69:2508-16. https://doi.org/10.1093/jac/dku177.

12. Vossen MG, Wenisch JM, Maier-Salamon A, Fritsch A, Saria K, Zuba C, et al. Doripenem treatment during continuous renal replacement therapy. Antimicrob Agents Chemother. 2015;60:1687-94. https://doi.org/10.1128/ AAC.01801-15.

13. Yamamoto T, Yasuno N, Katada S, Hisaka A, Hanafusa N, Noiri E, et al. Proposal of a pharmacokinetically optimized dosage regimen of antibiotics in patients receiving continuous hemodiafiltration. Antimicrob Agents Chemother. 2011;55:5804-12. https://doi.org/10.1128/AAC.01758-10.

14. Ikeda K, Ikawa K, Morikawa N, Kameda K, Urakawa N, Ohge H, et al. Quantification of doripenem in human plasma and peritoneal fluid by highperformance liquid chromatography with ultraviolet detection. J Chromatogr B Analyt Technol Biomed Life Sci. 2008;867:20-5. https://doi. org/10.1016/j.jchromb.2008.03.001.

15. Kuti JL, Dandekar PK, Nightingale CH, Nicolau DP. Use of Monte Carlo simulation to design an optimized pharmacodynamic dosing strategy for meropenem. J Clin Pharmacol. 2003;43:1116-23. https://doi.org/10.1177/ 0091270003257225 .

16. Yadav R, Bulitta JB, Nation RL, Landersdorfer CB. Optimization of synergistic combination regimens against carbapenem- and aminoglycoside-resistant clinical Pseudomonas aeruginosa isolates via mechanism-based pharmacokinetic/pharmacodynamic modeling. Antimicrob Agents Chemother. 2016:61:e01011-6. https://doi.org/10.1128/AAC.01011-16.

\section{Publisher's Note}

Springer Nature remains neutral with regard to jurisdictional claims in published maps and institutional affiliations.

Ready to submit your research? Choose BMC and benefit from:

- fast, convenient online submission

- thorough peer review by experienced researchers in your field

- rapid publication on acceptance

- support for research data, including large and complex data types

- gold Open Access which fosters wider collaboration and increased citations

- maximum visibility for your research: over $100 \mathrm{M}$ website views per year

At $\mathrm{BMC}$, research is always in progress.

Learn more biomedcentral.com/submissions 